\title{
Uma história de Benguela na economia do Atlântico Sul
}

\author{
Crislayne Gloss Marão Alfagali*
}

Candido, Mariana P. An African Slaving Port and the Atlantic World. Benguela and Its Hinterland (2013). Nova York: Cambridge University Press, 2015.

Este é um livro pioneiro: trata-se do primeiro trabalho exaustivo sobre um importante território angolano ao sul do rio Kwanza: Benguela, hoje uma das principais províncias do jovem país ${ }^{1}$ e, historicamente, durante mais de duzentos anos, o terceiro maior porto de embarque de escravos do Atlântico. O recorte temporal é abrangente, desde a primeira expedição portuguesa à localidade que ficou conhecida como "Benguela Velha”, no início do século XVI, até meados do século XIX, quando Benguela perde sua importância na economia atlântica devido à legislação que determina o fim

\footnotetext{
${ }^{1}$ Embora Benguela apareça como objeto de alguns estudos anteriores, é a primeira vez que lhe dedicam uma análise extensa, com vasta pesquisa arquivística e novas interpretaçóes. Exemplos de outros estudos sobre a temática são aqueles de Ralph Delgado que, escritos enquanto Angola ainda era colônia portuguesa, trazem muito do ponto de vista colonial: DELGADO, Ralph. A famosa e histórica Benguela: catálogo dos governadores, 1779 a 1940. Lisboa: Cosmos, 1944 e $O$ reino de Benguela. Do descobrimento à criação do governo subalterno. Lisboa: Imprensa Beleza, 1945.
}

do tráfico de escravos para o Brasil.

Mariana Candido, ao propor um diálogo assíduo com diversas correntes historiográficas, se insere em um conjunto de autores que abordam a história do continente africano a partir de uma perspectiva "afrocêntrica", tributária dos caminhos abertos por uma historiografia que se voltou para o estudo dos portos de escravos na África, centra sua análise na agência africana. ${ }^{2}$ Dessa forma, ao escrever a primeira história detalhada sobre Benguela e o seu hinterland - e a formação de seu porto no centro da economia escravista do Atlântico Sul — a autora destaca o papel das "pessoas que construíram esses lugares e o inseriram na economia global" (p. 24). E, ainda que não negue a importância da participação dos oficiais portugueses

\footnotetext{
${ }^{2}$ Alguns exemplos dessa historiografia: HEYWOOD, Linda M.; THORNTON, John. Central Africans, Atlantic Creoles and the Making of the Foundation of the Americas, 1585-1660. Nova York: Cambridge University Press, 2007; SWEET, James H. Recreating Africa: Culture, Kinship, and Religion in the African-Portuguese World, 1441-1770. Chapel Hill: University of North Caroline Press, 2003; LOVEJOY Paul E.; TROTMAN, David V. Enslaved Africans and their Expectations of Slave Life in the Americas: Towards a Reconsideration of Models of "Creolisation". In: SHEPHERD, Verene; RICHARDS, Glen L. (Ed.). Questioning Creole: Creolisation Discourses in Caribbean Culture. Kingston: Ian Randle, 2002, p. 67-91.
}

* Doutoranda em História pela Universidade Estadual de Campinas. Campinas, SP, Brasil E-mail: cgmalfagali@gmail.com. 
e de comerciantes estrangeiros nessa história, sua narrativa privilegia as trajetórias dos africanos e, como veremos, com enfoque nas mulheres africanas.

$\mathrm{O}$ conjunto de fontes que compóe essa análise é vasto e advém de três continentes; são documentos coloniais produzidos por portugueses, brasileiros e africanos - relatórios, cartas, ofícios, censos, dados de exportação, registros paroquiais, crônicas, relatos de viagem provenientes dos arquivos de Angola, Portugal, Brasil, Canadá e Estados Unidos. Consciente da limitação dos documentos coloniais, por serem produto de uma visão europeia, a autora se esforça para reconstruir uma história social da região afirmando que mesmo nas lacunas e nos silêncios é possível encontrar indícios do que foi destruído, transformado e criado pelos atores envolvidos (p. 23). Embora tenha recorrido a entrevistas, registros de missionários e antropólogos do século $\mathrm{XX}$ para complementar os dados insuficientes das fontes escritas, privilegia as informaçóes dos documentos que encontrou nos arquivos de Luanda e Benguela. ${ }^{3}$

Como debate historiográfico central, $A n$ African Slaving Port and the Atlantic World discute o impacto da economia Atlântica e do tráfico transatlântico de escravos nas sociedades da África Centro-Ocidental. Ao contrário do que defendem Thornton e Miller, ${ }^{4}$ Candido busca comprovar que as

\footnotetext{
${ }^{3}$ Vale lembrar que a guerra foi um fator desarticulador da reconstruçáo de alguns aspectos da tradição oral, da memória das geraçóes passadas na África Central.

${ }^{4}$ THORNTON, John. The slave trade in eighteenth century Angola: effects of demographic structu-
}

transformaçóes provocadas na organização social, política, cultural e econômica dos Ndombe - um dos povos que primeiro estabeleceu contato com os portugueses na região - e de outros grupos vizinhos deixaram marcas devastadoras, pois levaram à expansão do colonialismo, à dependência africana da economia Atlântica, à instabilidade e perda de autonomia política e à violência incitadas pelos constantes (e, ao longo do tempo, cada vez maiores e mais frequentes) conflitos que tinham por objetivo o apresamento de escravos. Para a autora, esses fatos não podem ser desvinculados da situação de declínio econômico e político enfrentada pelos africanos no final do século XIX.

De maneira eloquente, vemos surgir a emergência de uma sociedade escravista na África e os efeitos do colonialismo português na desarticulação dos estados africanos. Embora estudos quantitativos já tenham informado sobre os impactos do tráfico transatlântico ${ }^{5}$ — número de cativos exportados, a relevância da reprodução natural, os núme-

re. Canadian Journal of African Studies, v. 14, n. 3, p. 417-427, 1980; MILLER, Joseph C. The significance of drought, disease and famine in the agriculturally marginal zones of West-Central Africa. Journal of African History, v. 23, n. 1, p. 17-61, 1982; MILLER, Joseph C. Way of death: Merchant Capitalism and the Angolan Slave Trade, 1730-1830. Madison: University of Wisconsin Press, 1988.

${ }^{5}$ Exemplos de estudos quantitativos sobre o tráfico transatlântico: CURTIN, Philip. The Atlantic Slave Trade: A Census. Madison: University of Wisconsin Press, 1969; ELTIS, David. Economic Growth and the Ending of the Transatlantic Slave Trade. Nova York: Oxford University Press, 1987; ELTIS, David; RICHARDSON, David (Org.). Extending the Frontiers: Essays on the New Transatlantic Slave Trade Database. New Haven e Londres: Yale University Press, 2008. 
ros da produção alimentícia —, eles negligenciam as transformaçóes sociais, tal como a dependência local do trabalho escravo (p. 14). A escravidão se tornou em Benguela, como em outras colônias, o elemento fundante da ordem econômica e social, e foi por meio da ação de seus agentes (traficantes, oficiais coloniais, entre outros) que a colonização se instaurou: a língua portuguesa, a religião católica, novos padróes de alimentação e consumo, mudanças nas relaçóes de gênero.

A estrutura do livro se divide em dois capítulos introdutórios que cobrem a história de Benguela até 1850 e três capítulos temáticos em que a autora aborda com mais detalhes algumas questôes. An African Slaving Port and the Atlantic World traz a descrição dos estágios da colonização portuguesa em Benguela dos primeiros contatos, que foram atraídos pelas notícias da abundância de cobre na região e de uma grande densidade populacional, em fins do século XVI, até quando todo um esforço de colonização teria conferido uma maior estabilidade à presença portuguesa, ao longo do século XVIII. Logo que o acesso às minas de cobre foi dificultado pelas chefias africanas, o tráfico de pessoas foi eleito como o comércio mais rentável.

$\mathrm{O}$ porto de Benguela se tornou o centro do colonialismo português e do tráfico de escravos ao sul do rio Kwanza. Uma das questóes defendidas neste trabalho é a centralidade deste porto para o tráfico transatlântico já no século XVII, explicada tanto pelos dados demográficos do tráfico quanto pela invasão holandesa de 1641-1648: "Se a exportação de escravos não era importante em Benguela, por volta de 1640, como podemos explicar a invasão e ocupação holandesas"? (p. 69). Para além da costa e mesmo ao longo dela, a colonização portuguesa não se fazia forte ou impenetrável. Os poucos homens nas guarniçôes já reduzidas, espalhadas pelos presídios e feiras que foram surgindo, estavam debaixo da constante ameaça dos africanos e de outros europeus.

Muitas chefias que desafiaram a presença portuguesa nas primeiras décadas do século XVIII desaparecem nos relatos dos anos seguintes. Isso é interpretado como um indício de como o tráfico transatlântico levou ao colapso antigos domínios centro-africanos e, por conseguinte, à sua fragmentação política e a ciclos de violência que traziam fome, insegurança e possibilitavam a captura massiva de cativos. Essas premissas são comprovadas no estudo da reconfiguração política dos estados de Wambu, Mbailundu e Viye. As próprias identidades que assumiam as vítimas do tráfico de Benguela ao chegarem nos portos de destino (em sua maioria, eram enviados para o Brasil) — Kitata, Kalukembe, Kitete, Mbailundu e Wammbu — eram resultado de um processo fluido de migração: em busca de proteção e segurança contra os mecanismos de escravizaçáo, as pessoas se anexavam a uma ou a outra chefia local. Assim, a identidade étnica hoje conhecida como Ovimbundu, um grupo coeso do interior de Angola, não existia na era do tráfico transatlântico; essa singularidade foi construída posteriormente (p. 292 e ss.).

No seu compromisso de dar nome e rosto aos números da demografia da escravidão, Mariana Candido segue os esparsos 
registros que a documentação oficial deixou para reconstruir as trajetórias de homens e mulheres que foram escravizados. Os processos e mecanismos de escravização - guerra justa, razias, sequestros, condenação judicial, escravidão por dívida, punição por crime — são analisados à luz da luta de Quitéria, Juliana, Albano, Katete, Vitória, Nbena, José Manuel e outras pessoas que, enquanto agentes históricos, utilizaram todos os seus recursos à procura de alguma segurança, equilibrando-se na linha tênue que determinava as formas legais e ilegais de escravização. Essas histórias mostram que a escravidão era uma ameaça a todos: tanto os que moravam ao longo da costa e que, sendo vassalos da Coroa, eram cristãos, dominavam o português, e, portanto, estariam protegidos pela legislação portuguesa, quanto os gentios que habitavam o interior. Candido contesta nesse ponto a tese de Joseph Miller segundo a qual a fronteira da escravidão se moveria cronológica e progressivamente para o interior do continente africano, criando uma margem de proteção para os moradores do litoral. ${ }^{6}$

A noção de crioulização sustenta muitos argumentos da presente obra. Apoiando-se sobretudo nos apontamentos de James Sweet, ${ }^{7}$ a autora defende que só é possível compreender a crioulização em sua relação íntima com o tráfico de escravos e o colonialismo, como uma transformação socio-

\footnotetext{
${ }^{6}$ MILLER, Joseph C. Way of Death: Merchant Capitalism and the Angolan Slave Trade, 1730-1830, op. cit., p. 140-169.

SWEET, James H. Recreating Africa: Culture, Kinship, and Religion in the African-Portuguese World, 1441-1770, op. cit.
}

cultural; não uma ocidentalização ou aculturação, pois as resistências aos elementos da cultura europeia eram evidentes — tais como o sincretismo religioso e a persistência da poligamia (p. 12). O conceito é visto como uma via de mão dupla, em que tanto as instituiçóes portuguesas tinham de se ajustar às mudanças provocadas por elementos africanos, quanto os estados africanos se viam obrigados a ceder espaço na violenta negociação com as forças coloniais. ${ }^{8}$

Os autos de vassalagem colonial, tratados em que as autoridades centro-africanas — os sobas — oficializavam sua sujeição à Coroa portuguesa, mediante o estabelecimento de obrigaçóes e direitos definidos para os dois lados, se misturavam com as cerimônias de undamento locais. Ao undar, deitar pó ou farinha no corpo de um novo chefe, os mais velhos da comunidade confirmavam sua autoridade e poder. $\mathrm{O}$ mesmo procedimento foi adotado pelos portugueses, que, ao ratificarem suas alianças, undavam o soba que passava a lhes ser sujeito.

O conceito de crioulização também é desenvolvido ao analisar a participação de portugueses, brasileiros, filhos da terra (nascidos na colônia) na formação das sociedades Luso-Africanas em Benguela e seu interior; trata-se de grupos de uma nova elite intrinsecamente ligada ao estado colonial. A presença de brasileiros é realçada devido, entre outras razóes, ao intenso tráfico de es-

\footnotetext{
${ }^{8}$ Seguindo a interpretação de Hawthorne, para os africanos, a crioulização era um exemplo de uma criatividade cultural sob opressáo. HAWTHORNE, Walter. From Africa to Brazil: Culture, Identity and an Atlantic Slave Trade, 1600-1800. Nova York: Cambridge University Press, 2010.
} 
cravos que a colônia americana demandava e, assim, ao constante trânsito de traficantes ou degredados brasileiros que iam se instalando na margem africana do Atlântico Sul.

Se o papel das mulheres é abordado de forma transversal em An African Slaving Port and the Atlantic World, é ao descrever o papel econômico e cultural das mulheres africanas que a temática ganha peso. As donas, mulheres que se envolviam com portugueses ou brasileiros e que acumulavam riquezas, eram responsáveis por um grande número de dependentes, pelo funcionamento do tráfico de escravos, o cultivo de alimentos e a comercialização de mercadorias. Além disso, "elas assumiam a responsabilidade que reproduzir hierarquias sociais, enfatizando sua aliança com a Igreja Católica e com o comércio Atlântico (p. 135) ”.

No decorrer do livro, Candido se lança a um esforço de comparação com outras realidades coloniais, assim, aparecem ligaçóes com a África Ocidental, a América Hispânica, com os imperialismos britânico e francês. Do mesmo modo, dialoga com a historiografia brasileira em temas fulcrais como a polissemia dos termos que aparecem nas fontes coloniais, que ora determinariam a cor da tez, ora a condição social. Contudo, ao descrever os mecanismos de escravização de africanos e luso-africanos, uma maior aproximação dos estudos sobre o aprisionamento e a escravização de indígenas no Brasil poderia lançar novas questôes, além de renovar algumas interpretaçôes.' Entretanto, a forma eloquente e balanceada como os argumentos são construídos em torno do problema histórico do colonialismo é precisa. Trata-se de um estudo de fôlego com vasta pesquisa histórica e densa reflexão, incontornável aos que se dedicam à análise da História da África e dos africanos, da escravidão e da formação do império português.

\footnotetext{
${ }^{9}$ MONTEIRO, John. Negros da terra. Índios e bandeirantes nas origens de São Paulo. São Paulo: Companhia das Letras, 1994.
} 